
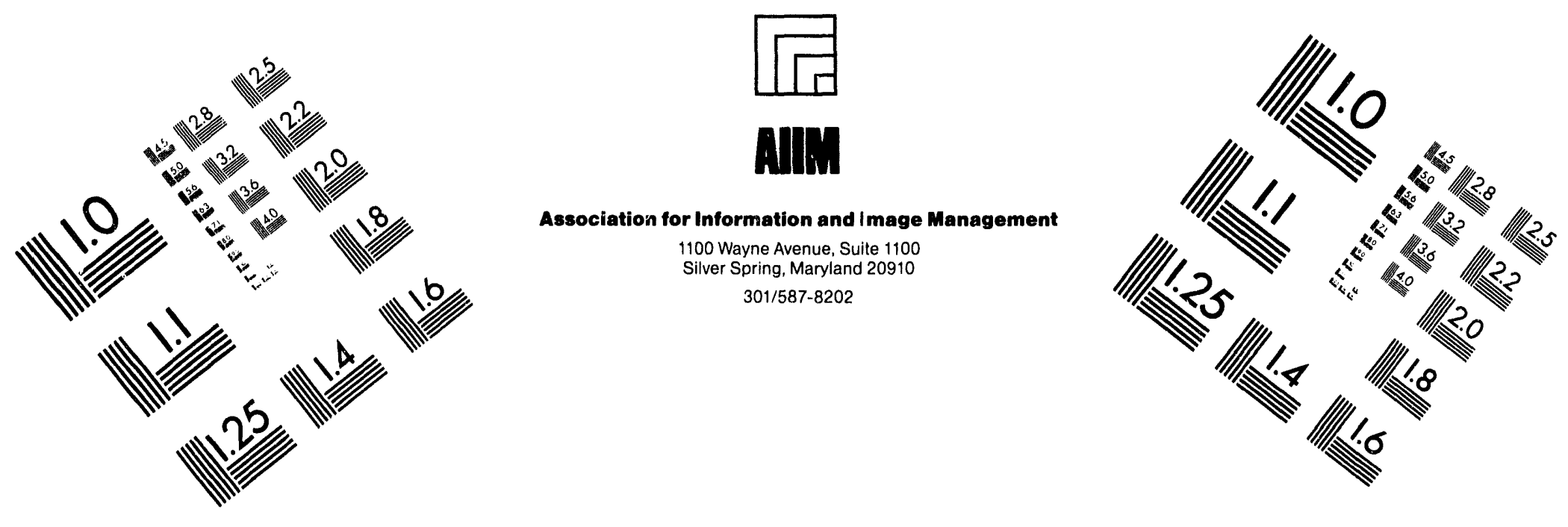

\title{
Centimeter
}

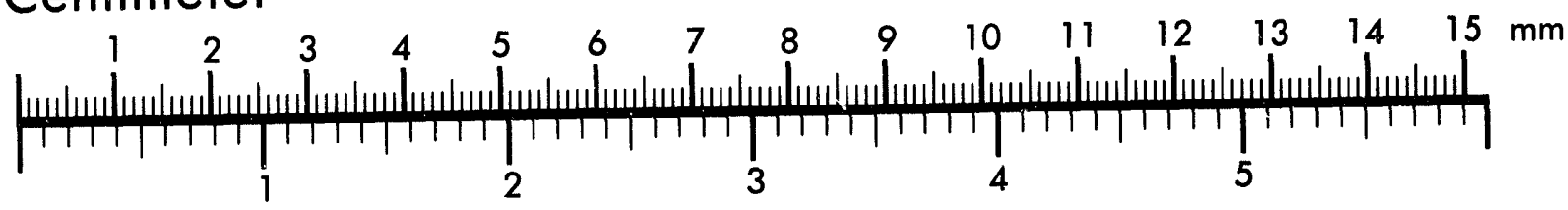
Inches
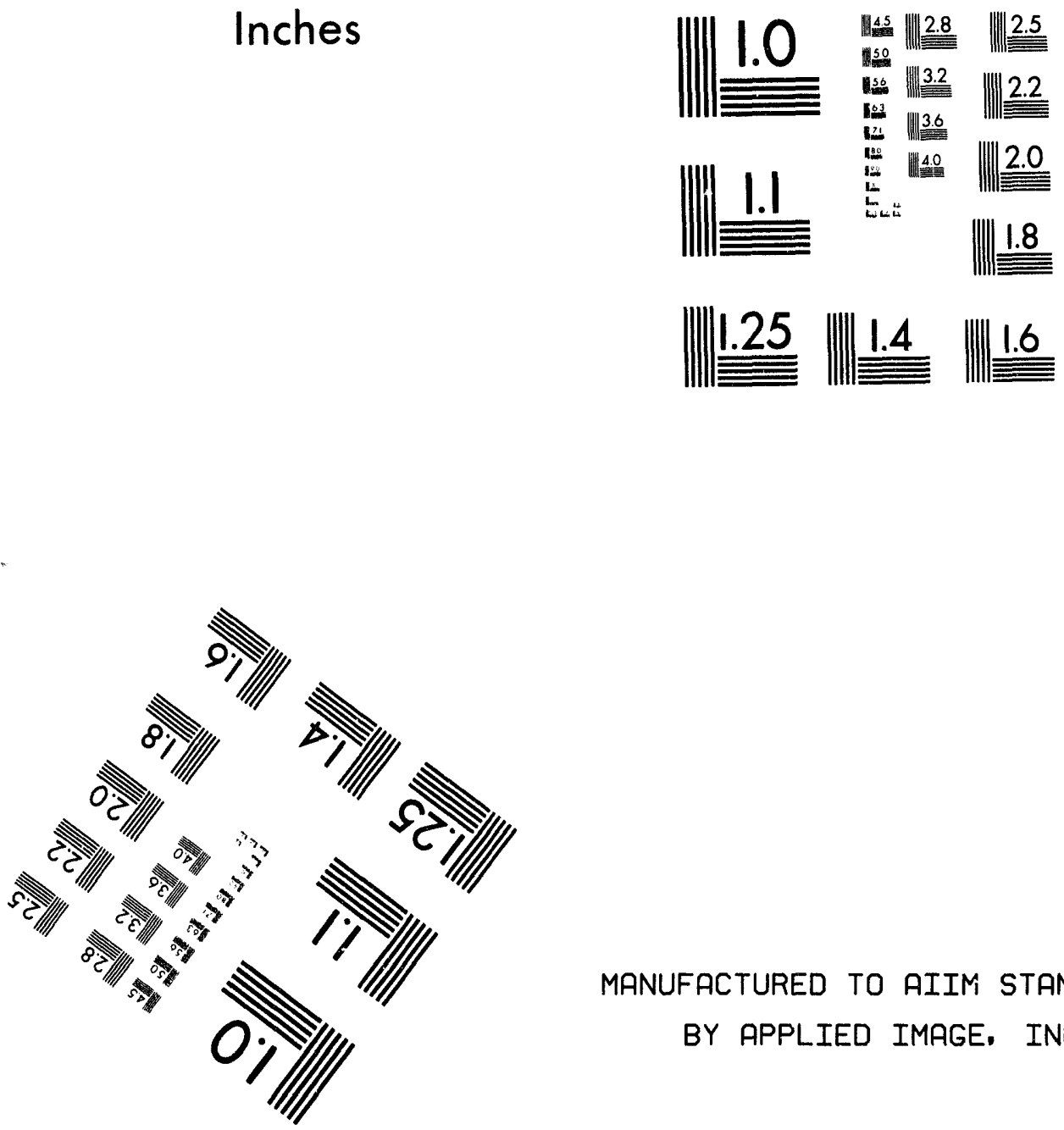

MANUFACTURED TO AIIM STANDARDS BY APPLIED IMAGE, INC.

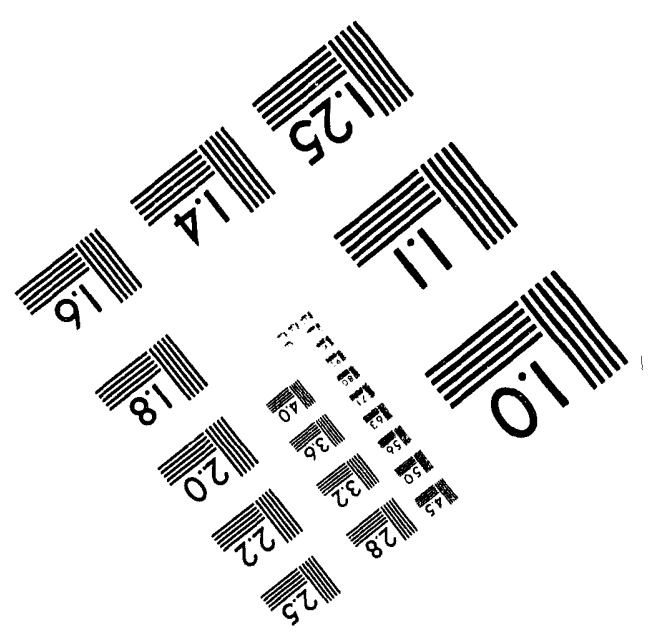



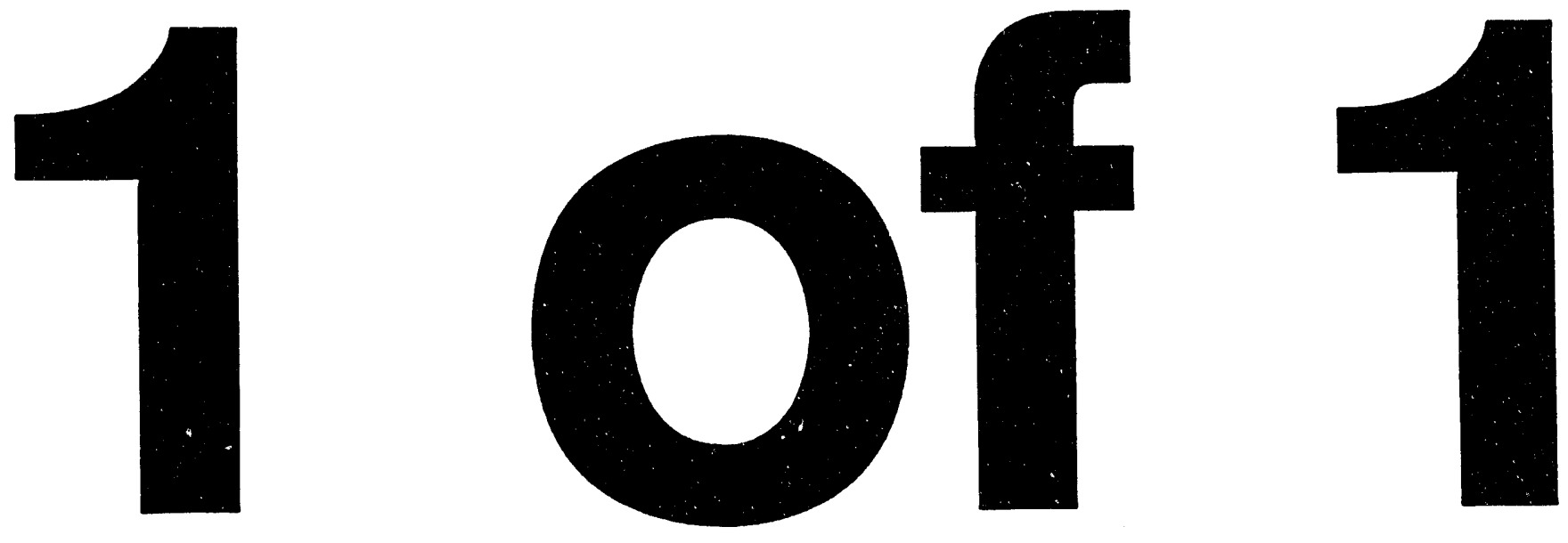


\section{MICROSTRUCTURE AND DENSITY CHANGES OF Li20 DURING IRRADIATION IN BEATRIX-II, PHASE I}

T. Takahashi

K. Noda

O. D. Slagle

F. D. Hobbs

June 1994

Presented at the

Third International Symposium

of Fusion Nuclear Technology

June 27 - July 1, 1994

Los Angeles, California

Prepared for

the U.S. Department of Energy

under Contract DE-AC06-76RLO 1830

Pacific Northwest Laboratory

Richland, Washington 99352

DISTRIBUTION OF THIS DOCUMENT IS UNLIMITED

\section{DISCLAIMER}

This report was prepared as an account of work sponsored by an agency of the United States Government. Neither the United States Government nor any agency thereof, nor any of their employees, makes any warranty, express or implied, or assumes any legal liability or responsibility for the accuracy, completeness, or usefulness of any information, apparatus, product, or process disclosed, or represents that its use would not infringe privately owned rights. Refercnce herein to any specific commercial product, process, or service by trade name, trademark, manufacturer, or otherwise does not necessarily constitute or imply its endorsement, recommendation, or favoring by the United States Government or any agency thereof. The views and opinions of authors expressed herein do not necessarily state or refiect those of the United States Government or any agency thereof. 


\author{
Microstructure and Density Changes of Li20 during Irradiation \\ in BEATRIX-II, Phase I \\ T. Takahashi and $K$. Noda \\ Japan Atomic Energy Research Institute \\ Tokai-mura, Naka-gun, Ibaraki-ken, 319-11 Japan \\ 0. D. Slagle and F. D. Hobbs \\ Pacific Northwest Laboratory(a) \\ Richland, Washington 99352 U.S.A.
}

\begin{abstract}
BEATRIX-II, Phase I was an in situ tritium recovery experiment carried out on $\mathrm{Li}_{2} \mathrm{O}$ to $1 \mathrm{ithium}$ burnups in excess of $4 \%$. Solid $\mathrm{Li}, \mathrm{O}$ specimens were irradiated under a temperature gradient in the range from $700 \mathrm{~K}$ at the outer diameter to $1270 \mathrm{~K}$ at the center. A ring specimen of $\mathrm{Li}_{2} 0$ operated at a nearly uniform temperature with the capability of changing temperature in the range from 780 to $920 \mathrm{~K}$. Li 0 single crystals having two different ${ }^{6} \mathrm{Li}$ enrichments $(0.07$ and 1.8 at\%) were irradiated at $650 \mathrm{~K}$ in nonvented canisters. Microstructures of these specimens, before and after irradiation, were investigated using optical and scanning electron microscopy.

Substantial microsiructure change was found to have occurred in the solid specimen during irradiation and this change was characterized by the development of large columnar grains, lenticular porosity and a center void. The development of columnar grains and the formation of the center void was attributed to the migration of lenticular pores up the thermal gradient by a vaporization/condensation process. Morphological changes on fracture surfaces were observed both for the polycrystalline (solid and ring) specimens and the single crystal specimens. Measurements of density were used to further characterize the effects of irradiation on the open and closed porosity distributions in all the specimens. Although extensive microstructural and density changes occurred during irradiation, these changes had no significant impact on the integrity of $\mathrm{Li}_{2} \mathrm{O}$ during irradiation, and therefore these results support the use of $\mathrm{Li}_{2}^{2} \mathrm{O}$ as a fusion solid breeders.
\end{abstract}

(a) Pacific Northwest Laboratory is operated for the U. S. Department of Energy by Battelle Memorial Institute under Contact DE-ACO6-76RLO 1830. 


\subsection{INTRODUCTION}

Ceramic breeders in fusion blanket applications are exposed to severe neutronic environments and the expected property changes after high lithium burnups could affect their performance. Irradiation testing to high burnups under the fusion blanket conditions is important to resolve outstanding performance issues for ceramic breeders. The BEATRIX-II irradiation test is an IEA collaborative program to evaluate tritium release behavior and the irradiation integrity of ceramic breeders to high lithium burnups in a fusion blanket simulated neutronic environment[1,2]. In BEATRIX-II Phase I, in-situ tritium recovery experiments on $L i_{,} 0$ sintered specimens were carried out for 300 effective full power days (EFPD) in the Fast Flux Test Facility (FFTF) to attain lithium burnups in excess of $4 \%$. Li, 0 single crystal specimens were irradiated in closed canisters to specifically study radiation damage in $\mathrm{Li}_{2} 0$. Significant insight into in situ tritium recovery, irradiation integrity, and radiation damage has been obtained to date in BEATRIX-II, Phase I irradiation tests [3-6]. This paper presents the results of microstructural and density changes for the BEATRIX-II, Phase I $\mathrm{Li}_{2} 0$ specimens as determined during the postirradiation examination (PIE).

\subsection{EXPERIMENTAL}

\subsection{SPECIMENS}

Two in situ tritium recovery canisters were irradiated in BEATRIX-II, Phase I: a temperature-gradient canister containing a stack of solid $\mathrm{Li}_{2} \mathrm{O}$ pellets and a temperature change-canister containing a thin-ring $\mathrm{Li}_{2} \mathrm{O}$ specimen. The solid specimens were irradiated under a temperature gradient in the range from $700 \mathrm{~K}$ at the outer diameter to $1270 \mathrm{~K}$ at the center. A ring specimen operated at a nearly uniform temperature with the capability of changing temperature in the range from 780 to $920 \mathrm{~K}$. The temperature difference across the specimen was predicted to be $40 \mathrm{~K}$. The solid and the ring specimens were irradiated to a lithium burnup in excess of $4 \%$ in helium sweep gases containing from 0 to $1.0 \%$ hydrogen.

The stack of solid $\mathrm{Li}_{2} \mathrm{O}$ pellets in the temperature-gradient canister consisted of 11 pellets: $17 \mathrm{~mm}$ in diameter and a total length of $89 \mathrm{~mm}$. Densities ranged from 84.5 to $92.6 \%$ TD with grain sizes from 25 to $45 \mu \mathrm{m}$, increasing with the density of the specimens. The ring specimen in the temperature-change canister was $18.4 \mathrm{~mm}$ in diameter, $89 \mathrm{~mm}$ in length and $1.6-1.7 \mathrm{~mm}$ in thickness. The density was $80 \%$ TD with a grain size of $5 \mu \mathrm{m}$. Both specimens had ${ }^{L} \mathrm{~L} i$ enrichments of 61 at\%. The fabrication procedures of the specimens have been described el sewhere [7-8].

$\mathrm{Li}_{2} 0$ single crystals having two different ${ }^{6} \mathrm{Li}$ enrichments $(0.07$ and 1.8 at\%) were irradiated to $3.9 \times 10^{26} \mathrm{n} / \mathrm{m}^{2}$ (300 EFPD) in closed capsules. The capsule temperature during irradiation was approximately $650 \mathrm{~K}$ (i.e., the inlet sodium temperature in FFTF) and because of the low heat generation (due to the low ${ }^{6} \mathrm{Li}$ content) the inner temperatures of the specimens were not expected to be much higher than $650 \mathrm{~K}$. 


\subsection{MICROSTRUCTURE OBSERVATION}

Optical microscopy for the solid specimer. was carried out using a pellet section taken from a location near the axial center of the solid specimen stack. A radial section of the specimen was obtained by cutting a thin plate $2 \mathrm{~mm}$ in thickness. This section was polished with emery papers and diamond paste in an inert-gas atmosphere glove box to avoid chemical attack of moisture on the $\mathrm{Li}_{2} \mathrm{O}$ specimen. The surface of the polished specimens was etched by exposure to moisture-containing room air. Optical microscopy was carried out after the polished section was placed in a specially designed fixture which kept the specimen in a dry atmosphere.

Scanning electron microscopy (SEM) of the solid specimen, was carried out on rectangular specimens $(2 \mathrm{~mm} \times 2 \mathrm{~mm} \times 6 \mathrm{~mm})$ that were oriented with a long side parallel to the radial direction of the solid specimen. These specimens were further fractured perpendicular to the radius to give four samples representative of four radial positions. SEM observation of the ring specimen was carried out using rectangular specimens taken from the top, the center, and the bottom parts of the specimens. Freshly prepared fracture surfaces were used for SEM observation. For the single crystal specimens, the samples for SEM observation were prepared by cleaving the specimens. The majority of the sample preparation procedure for SEM observation was done in an inert atmosphere glove box to avoid influences due to moisture. However, gold coating and transfers to the microscope involved air exposure. SEM observation was carried out using JEOL JST-35 operated at 20 and $25 \mathrm{KeV}$.

\subsection{DENSITY AND POROSITY MEASUREMENTS}

The density and the associated porosities of the solid, the ring, and the single crystal specimens were determined in an inert atmosphere (argon) glove box by the "Archimedes method" using xylene. The measurement procedure involved weighing the specimen in xylene with and without filling the open porosity with xylene. Vacuum impregnation was used to fill the open porosity. These measurements result in the determination of the bulk density which includes both the open and closed porosity and the apparent density which includes only the closed porosity.

\subsection{RESULTS AND DISCUSSION}

\subsection{CERAMOGRAPY OF THE Li ${ }_{2} 0$ SOLID SPECIMENS}

Figure 1 is an optical micrograph of a radial cross section of the irradiated $\mathrm{Li}_{2} \mathrm{O}$ solid specimen. The microstructure was found to have changed significantly during irradiation. The two most pronounced changes are the formation of a center void and extensive grain growth. The radial cross section in Figure 1 was taken from an originaly solid pellet and after irradiation a $4.5 \mathrm{~mm}$ center void was found to have formed[5]. Extensive columnar grain growth has occurred along the radial direction parallel to the the large temperature gradient in the specimen during irradiation.

The postirradiation microstructure can be described as a series of four different microstructural regions. In the region from the outer surface to 
$500 \mu \mathrm{m}$, i.e., the outer region, the microstructure resembles the original asfabricated microstructure with an average in grain size of $45 \mu \mathrm{m}$.

Temperatures in this outer region were 700-800 $\mathrm{K}$ during irradiation. At these relatively low temperatures, grain growth did not take place. For the region between 500 to $1500 \mu \mathrm{m}$ from the surface, equiaxed grain growth was observed and the grain size was on the order of $100 \mu \mathrm{m}$. In the region between 1500 to $5500 \mu \mathrm{m}$ from the surface, columnar grains were developed along the radial direction, i.e., parallel to the temperature gradient. This columnar growth region is shown in detail in Figure 2. In the higher temperature region with the large temperature gradient, columnar grains were found to occur with widths up to $200 \mu \mathrm{m}$ and lengths as long as $1500 \mu \mathrm{m}$. Typically, each columnar grain had a lenticular pore located at the high temperature end. For the region within $500 \mu \mathrm{m}$ of the inner surface of the center void, short columnar grains and large equiaxed grains were observed.

The final microstructure of the $\mathrm{Li}_{2} \mathrm{O}$ solid specimen is very similar to microstructures that develop in fisssion fuels[9]. Fission fuels have been found to develop the same series of microstructuri regions as the temperature increases in a thermal gradient. Because of the similarity of the configuration of the columnar grains and the lenticular pores in the $\mathrm{Li}_{2} \mathrm{O}$ solid specimen to those seen in fission fuels, it would appear that there were a similar grain growth mechanisms operating in both cases. In fission fuels the development of the columnar grains is attributed to the migration of the lenticular pores up the temperature gradient by an evaporation-condensation process. In the process of columnar grain growth, the lenticular pores sweep the as-fabricated porosity and the porosity formed from generated helium up the thermal gradient to contribute to the formation of the center void in the solid specimen.

The evaporation-condensation process for the columnar grain growth requires high temperatures and large temperature gradients to effect significant rates of evaporation and transport of the material. The microstructural change along the radial direction of the solid specimen reflects the change of temperature conditions mentioned below: 1) In the outer region, insufficient temperatures for the grain growth, 2) in the region in which equiaxed grain growth occurred, sufficient temperatures for equiaxed grain growth but not for the columnar grain growth, 3) in the region of well-developed columnar grains, sufficient temperature and temperature gradient for the substantial columnar grain growth, 4) in the inner region, sufficient temperature for grain growth but insufficient temperature gradient for substantial columnar grain growth.

\subsection{SEM MICROSTRUCTURES}

SEM observations were carried out on fracture surfaces from the solid specimen at various positions along the radius. Figure 3 shows scanning electron micrographs taken of fracture surfaces at various position in the radial direction of the solid specimen. For the outer region where the temperature was in the range $700-800 \mathrm{~K}$ and the original grain size was retained (Figure 3 (a)), a surface morphology was observed which could be described as blisters with wrinkles. This type of morphology was not observed in the unirradiated specimens and will be referred to as surface Type 
A. In the region where the columnar grains had developed (Figure 3 (b)), there was no change in surface morphology between the unirradiated and irradiated specimens. For the inner region near the center void (Figure 3 (c)), the surface morphology was observe to resemble blisters but the blisters had no wrinkles. This will be referred to a surface Type B.

For the ring specimen SEM observations were carried out on fractured surfaces from different axial positions. The original porosity was observed to increase, especially for specimen near the center (axial) part of the specimen. Although the grains size typically increased from the original grains size of $5 \mu \mathrm{m}$ to approximately $10 \mu \mathrm{m}$, no columnar grain growth was observed. In respect to the surface morphology, Type $A$ surfaces was observed for the bottom and center parts of the specimens, while Type B surfaces were observed for the center and the top parts of the specimens.

Figure 4 shows scanning electron micrographs of fractured surfaces of the single crystals specimens: a) the specimen with ${ }^{6} L i$ concentration of 1.8 at\% before irradiation, b) the specimen with ${ }^{6} L i$ concentration of 1.8 at\% after irradiation, c) the specimen with ${ }^{6} \mathrm{Li}$ concentration of 0.07 at\% after irradiation. For the before irradiation specimen with ${ }^{6} \mathrm{Li}$ concentration of 1.8 at\%, only a flat smooth surface was observed in the SEM. After irradiation a Type A surface was found. For the specimen with ${ }^{6} \mathrm{Li}$ concentration of 0.07 at\%, only a slight surface morphology change was observed after irradiation.

The Type A surface morphology found in the outer region of solid specimen and in the ring specimen was also observed for fractured surfaces of the single crystal specimens with ${ }^{6} \mathrm{Li}$ concentration of 1.8 at\%. In the single crystal specimens, spectroscopic observations have been obtained which were consistent with the occurrence of colloidal lithium metal centers during irradiation [6]. If formed, the colloidal lithium metal centers are expected to recover at temperatures greater than $870 \mathrm{~K}[10]$. The temperature of the ring specimen was kept at $920 \mathrm{~K}$ for several days at the end of irradiation, and it is, therefore, considered that if lithium colloidal metal centers had formed in the ring specimen they would have recovered in the final heat treatment. This means that the surface Type A morphology change observed in the ring specimen cannot be attributed to the colloidal lithium metal centers Another possible cause of the morphology changes is helium bubbles. Helium generated during the irradiation can be assumed not to migrate substantially in the range of 700-800 $\mathrm{K}$ and, therefore, the helium retained in the outer (low temperature) region of the solid specimen cannot be expected to aggregate to form helium bubbles. Thus, it is can be assumed that helium gas did not contribute to formation of the Type A surface morphology change observed for the low temperature region of the solid specimen. The Type B surface morphology change was observed for the inner region of the solid specimen and the ring specimen, where the temperatures in the range 920 to $1270 \mathrm{~K}$ were attained. At such temperatures, it is possible that the helium generated during the irradiation can migrate and form bubbles. Consequently, it is possible that the Type B morphology change may result from helium generation during the irradiation. However, the morphology change was quite different from that expected if the fracture surface had passed through helium bubbles leaving an observable pore. 
There is some possibility that a $\mathrm{LiOH}$ layer formed on the fracture surfaces of $\mathrm{Li}_{2} \mathrm{O}$ SEM samples during the handling of the samples. However, no surface morphology changes were observed for the unirradiated specimens nor for the columnar grain growth region in the solid specimen. The morphology change was also only minimal for the 0.07 at\% single crystals. The sample preparation procedure for SEM observation and the handling were the same for all the irradiated and unirradiated specimens. This suggests that the handling of the samples for SEM observation was appropriate and the LiOH layer affecting the surface morphology was not formed on the surface of the sample during the handling.

During irradiation, generated tritium in a form of dissolved tritiated water could be present in $L_{2} 0[11,12]$, and it is possible that this tritiated water could contribute to the surface morphology changes. Type A surfaces were found in specimens tending to have higher retained tritium inventories such as the outer regions of the solid specimen. Furthermore, it was predicted in the calculation study by $M$. C. Billone that the minimum tritium inventory for the BEATRIX-II solid specimen would not be at the inner hottest region but at an intermediate radial position [13, 14]. This prediction is in good agreement with the observation that no morphology change occurred in the columnar grain region.

For the single crystal specimens the amount of tritium generated in the specimen with ${ }^{6} \mathrm{Li}$ concentration of 1.8 at\% was larger than that in the specimen with ${ }^{6} \mathrm{Li}$ concentration of 0.07 at\%. A large fraction of generated tritium is expected to remain in the single crystal specimens, since the temperature during irradiation was lower than the temperatures at which substantial tritium release from the single crystals occurs. This seems to be consistent with the observations on the solid and ring specimens that the Type A surfaces are associated with higher retained tritium inventories.

\subsection{DENSITY AND POROSITY CHANGES}

Table 1 lists the bulk densities obtained from immersion density measurements and the apparent densities after vacuum impregnation/immersion. The measurements were carried out for irradiatied and nonirradiated specimens of the solid, ring, and single crystal specimens. The bulk density includes open and closed porosities while the apparent density is for the case where the open porosity is filled. The density values for before irradiation specimens are 1 isted in parentheses () in Table 1. The open porosities increase about $10 \%$ for the solid specimen and increase only slightly for tine single crystal specimens, while an almost insignificant change occurs for the ring specimen. The closed porosity of the solid specimens after the irradiation decreased by 3-6\%, while those of the ring and single crystal specimens increased by $8-10 \%$ and $3 \%$, respectively.

The increase in the open porosity of the solid specimen during irradiation suggests an increase in the porosity and cracks and this is consistent with the observed microstructure (Figure 1 and 2). The decrease in closed porosity for the solid specimen during irradiation was in agreement with the densification observed in the columnar grain region. For the ring specimen the open porosity remained about the same during irradiation but the closed porosity increased dramaticaly. The SEM studies indicated an increase in the size of the porosity and grain size during irradiation. This suggests 
that during irradiation the initial open porosity was consolidated into larger pores but did not increase in volume. The increase in closed porosity during irradiation for both the ring specimen and the single crystals may be associated with lithium burnup and swelling resulting from defect and/or helium bubble formation.

\subsection{CONCLUSIONS}

BEATRIX-II, Phase I was an in-situ tritium recovery experiment on sintered $\mathrm{Li}_{2} \mathrm{O}$ solid and ring specimens that was carried out to lithium burnups in excess of $4 \%$. Li, 0 single crystals were included in the irradiation experiment for radiation damage studies. Postirradiation examination of the irradiated $L_{2}, 0$ specimens was carried out to characterize the microstructural changes that occurred during irradiation. Ceramography on a radial section of the solid specimen indicated that the high temperatures and larger thermal gradients resulted in the development of a central void and large columnar grains which were associated with lenticular pores at the high temperature end. SEM studies of fracture surfaces for the polycrystalline (solid and ring) specimens and the single crystal specimens indicated the occurrence of morphology changes that resembled blisters with and without wrinkles. These changes were most pronounced for regions with the highest retained tritium inventories. Changes in specimen density or porosity during irradiation provided an additional insight into the microstructural changes that occurred for the three different specimens (solid, ring or single crystal) during irradiation. Although extensive microstructural and density changes occurred in these $\mathrm{Li}_{2} \mathrm{O}$ specimens, these changes did not significantly impact the irradiation integrity of $\mathrm{Li}_{2} \mathrm{O}$. Therefore these results support the conclusion that $L i, 0$ should be considered one of the leading candidates for use in a solid breeder fusion blanket application. 


\subsection{REFERENCES}

[1] G. W. Hollenberg, T. Kurasawa, H. Watanabe, S. E. Berk, I. J. Hasting, J. Miller, D. E. Baker, R. E. Bauer, and R. J. Puigh. 1989. "A Fast Neutron, In-situ Tritium Recovery Experiment on Solid Breeder Materials." Fusion Technol 15:1349-1353.

[2] G. W. Hollenberg, H. Watanabe, I. J. Hasting and S. E. Berk. 1992. "BEATRIX-II: A Multinational Solid Breeder Materials Experiment." J. Nucl. Mater. 191-194:23-29.

[3] K. Kurasawa, O. D. Slagle, G. W. Hollenberg, and R. A. Verrall. 1991. "In-situ Tritium Recovery From Li20 Irradiation in Fast Neutron Flux BEATRIX-II Initial Results." Fusion Technol. 19:931-937.

[4] 0. D. Slagle, T. Kurasawa, R. A. Verrall, and G. W. Hollenberg. 1992. "In Situ Tritium Recovery From Li20 Irradiated in Fast Neutron Flux BEATRIX-II Temperature Change Specimen." $\mathrm{J}$. Nucl. Mater. $191-194: 214-218$.

[5] 0. D. Slagle, T. Takahashi, F. D. Hobbs, K. Noda, D. L. Baldwin, G. W. Hollenberg, and R. A. Verrall. "Post Irradiation Examination of BEATRIX-II, Phase I." J. Nucl. Mater. in press, PNL-SA-22183, Pacific Northwest Laboratory, Richland, Washington..

[6] N. Masaki, K. Noda, H. Watanabe, R. G. Clemmer and G. W. Hollenberg. 1994. "Radiation Damage in Li,O Irradiated with Fast Neutrons" in Proceedings of International Workshop on Ceramic Breeder Blanket Interactions, September 22-24, 1993, Paris France, ed N. Roux, p 171176, Commissariat A L'Energie Atomique, Paris, France.

[7] 0. D. Slagle, K. Noda and T. Takahashi. 1990. "Fabrication of Lithium Ceramic Pellets, Rings, and Single Crystals for Irradiation in BEATRIX-II." Advances in Ceramics, Vo1. 27, pp. 77-93, The American Ceramic Society, Westerville, Ohio.

[8] T. Takahashi, and H. Watanabe. 1989. "Preparation and Characterization of Lithium Oxide." Fusion Energy Des. 8:399-405.

[9] D. R. 01 ander. 1976. "Fundamental Aspects of Nuclear Reactor Fuel Elements." TID 26711, p. 1, Technical Information Center - Energy Research and Development Administration.

[10] K. Noda. 1991. "Radiation Damage and Irradiation Effects in Solid Breeders." J. Nucl. Mater. 179-181:37-41.

[11] M. C. Billone, C. C. Lin, H. Attaya, and Y. Gohar. 1991. "Tritium Retention and Release Analysis for the U.S.-ITER Blanket." Eusion Technology, 19:976-983. 
[12] M. Tetenbaum, and C. E. Johnson. 1984. "Partial Pressures of H2O Above the Diphasic $\mathrm{Li}_{2} \mathrm{O}(\mathrm{s})-\mathrm{LiOH}(s, 1)$ System." J. NuCl. Mater. 126:25.

[13] M. C. Billone, and I. Gomes. 1993. "Validation of the TIARA code to BEATRIX-II Li20 Inventory Data." in Proceedings of International Workshop on Ceramic Breeder Blanket Interactions, September 22-24, 1993, Paris France, ed N. Roux, p 105-130, Commissariat A L'Energie Atomique, Paris, France.

[14] M. C. Billone. 1994. "Validation of the TIARA Code to Tritium Inventory Data." Presented at the Third International Workshop on Ceramic Breeder Blanket Interactions, University of California at Los Angeles, June 22-24, 1994. 
Figure Captions

Figure 1. An optical micrograph of a radial cross section of the $\mathrm{Li}_{2} \mathrm{O}$ solid specimen irradiated to lithium burnups in excess of $4 \%$.

Figure 2. An optical micrograph of the columnar grain region of the $\mathrm{Li}_{2} \mathrm{O}$ solid specimen with lenticular pores at the high temperature end of the grains and the microstructure adjacent to the center void.

Figure 3. Scanning electron micrographs of fractured surfaces at various radial positions in the $\mathrm{Li}_{2} \mathrm{O}$ solid specimen; a) the outer region, b) the region in which columnar grains were well developed, c) the inner region near the center void.

Figure 4. Scanning electron micrographs of fractured surfaces of the single crystal specimens; a) the specimen with ${ }^{6} \mathrm{~L} i$ concentration of 1.8 at\% before irradiation, b) the specimen with ${ }^{6} \mathrm{~L} i$ concentration of $1.8 \mathrm{at} \%$ after irradiation, $c)$ the specimen with ${ }^{6} \mathrm{Li}$ concentration of 0.07 at\% after irradiation. 
TABLE 1. Density and Porosity Results from the Postirradiation Examination of BEATRIX-II, Phase I. Values included in parentheses are for unirradiated archive specimens

\begin{tabular}{||l|l|l|l|l||}
\hline $\begin{array}{c}\text { Sample - } \\
\text { Axial Position }\end{array}$ & $\begin{array}{c}\text { Bulk Density } \\
\text { \%TD }\end{array}$ & $\begin{array}{c}\text { Apparent Density } \\
\text { \%TD }\end{array}$ & $\begin{array}{c}\text { Open Porosity } \\
\%\end{array}$ & $\begin{array}{c}\text { Closed Porosity } \\
\%\end{array}$ \\
\hline Solid - Center & $86.5(90.3)$ & $96.6(90.6)$ & $10.5(0.3)$ & $3.0(9.3)$ \\
\hline Ring - Upper & $71.2(79.4)$ & $87.1(97.3)$ & $18.2(18.4)$ & $10.5(2.1)$ \\
\hline Ring - Center & $72.3(79.4)$ & $85.4(97.3)$ & $15.3(18.4)$ & $12.3(2.1)$ \\
\hline Ring - Bottom & $71.8(79.4)$ & $87.0(97.3)$ & $17.6(18.4)$ & $10.6(2.1)$ \\
\hline Single 1.8 at\% & $95.9(98.8)$ & $96.4(99.5)$ & $1.4(0.8)$ & $3.5(0.4)$ \\
\hline Single 0.07 at\% & 98.5 & 99.1 & 0.5 & 1.0 \\
\hline
\end{tabular}




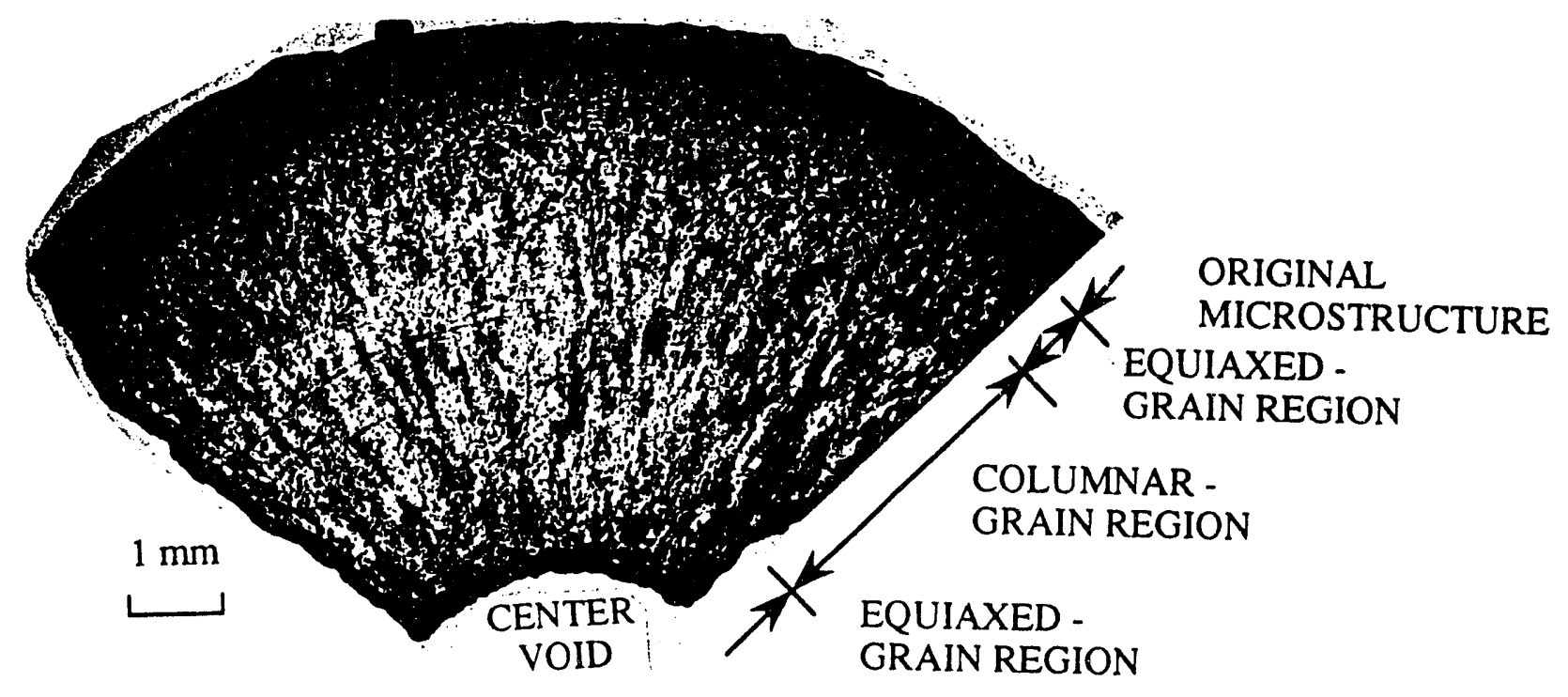

Figure 1 


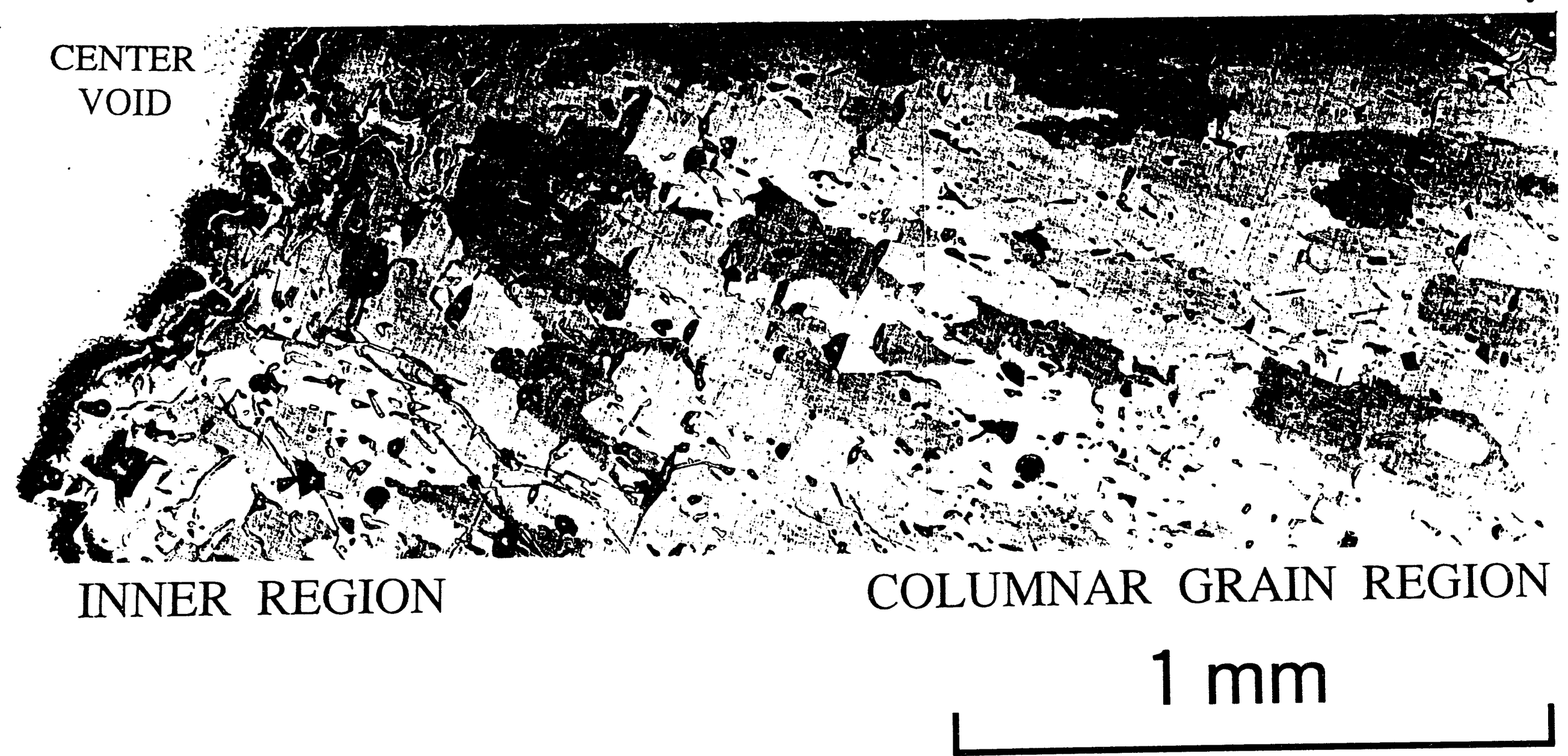

Figure 2 

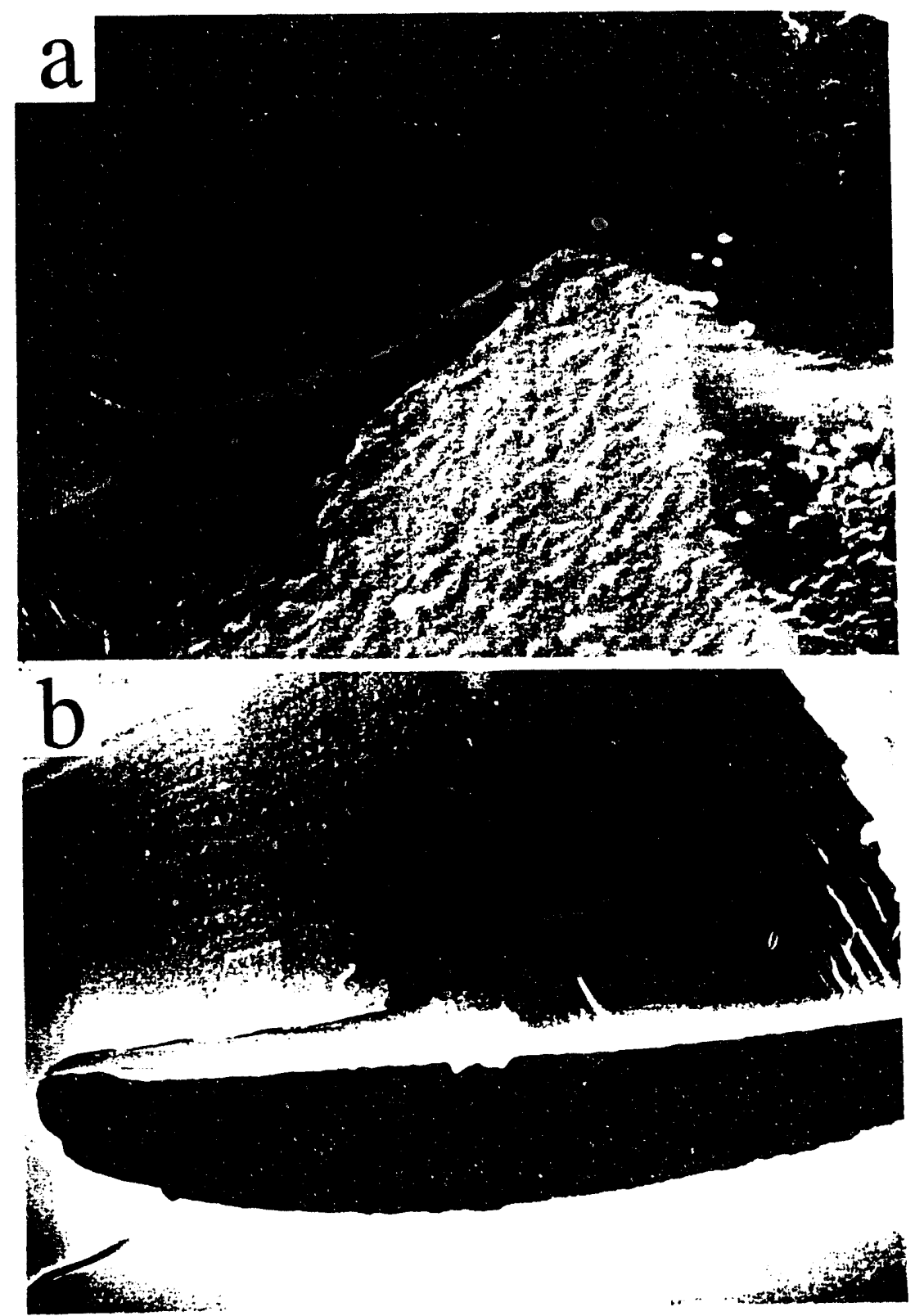

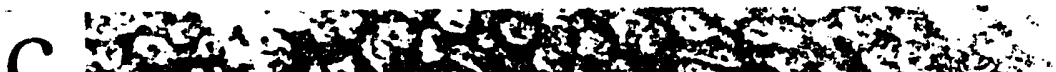
C

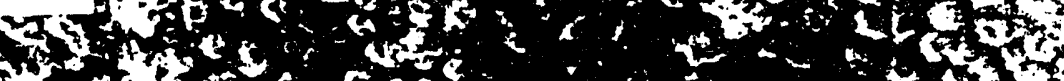

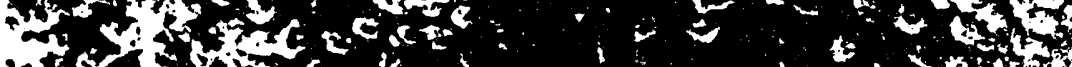

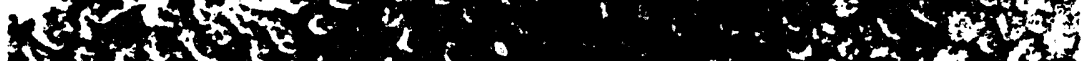

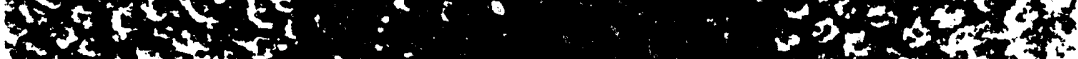

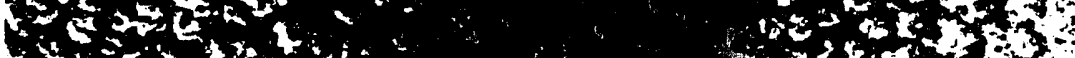

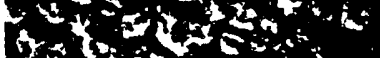

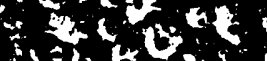

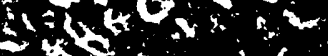

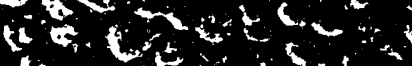

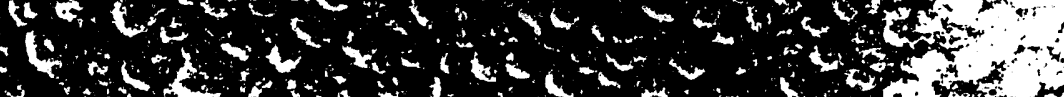

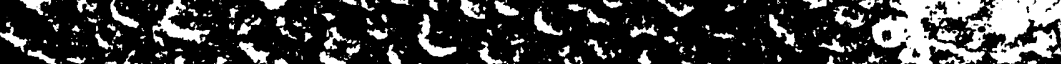

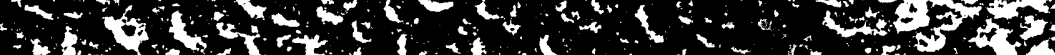

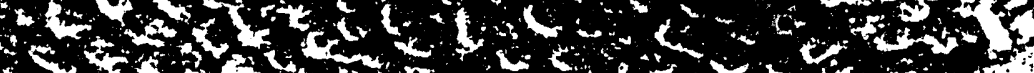

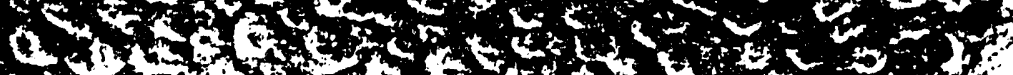

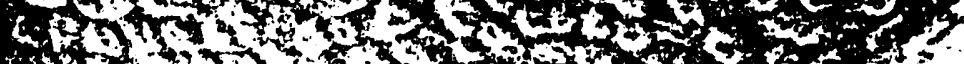




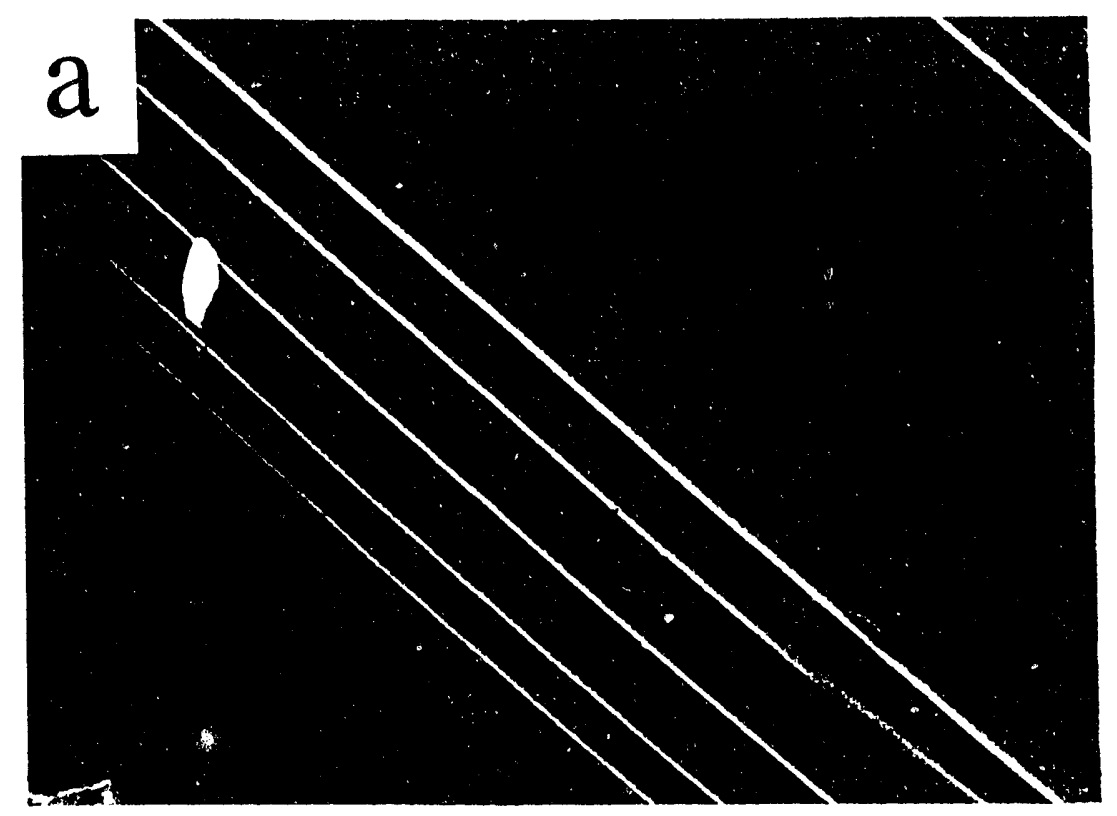
b 1 W

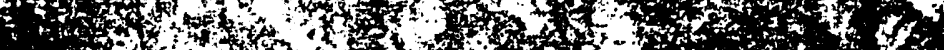

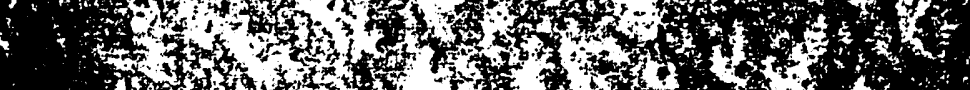

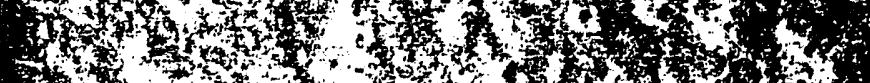

7 mon

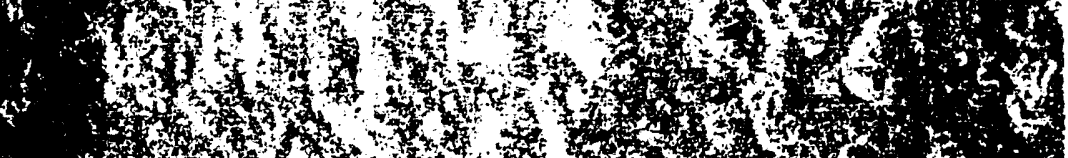

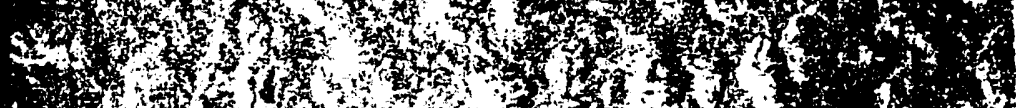

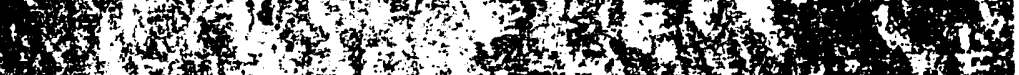

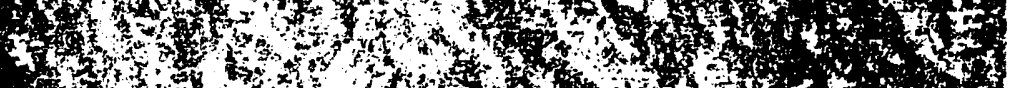

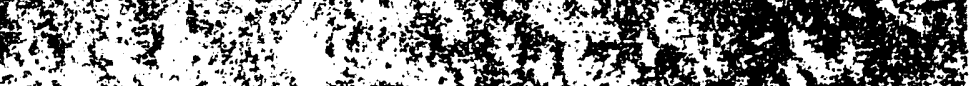
135

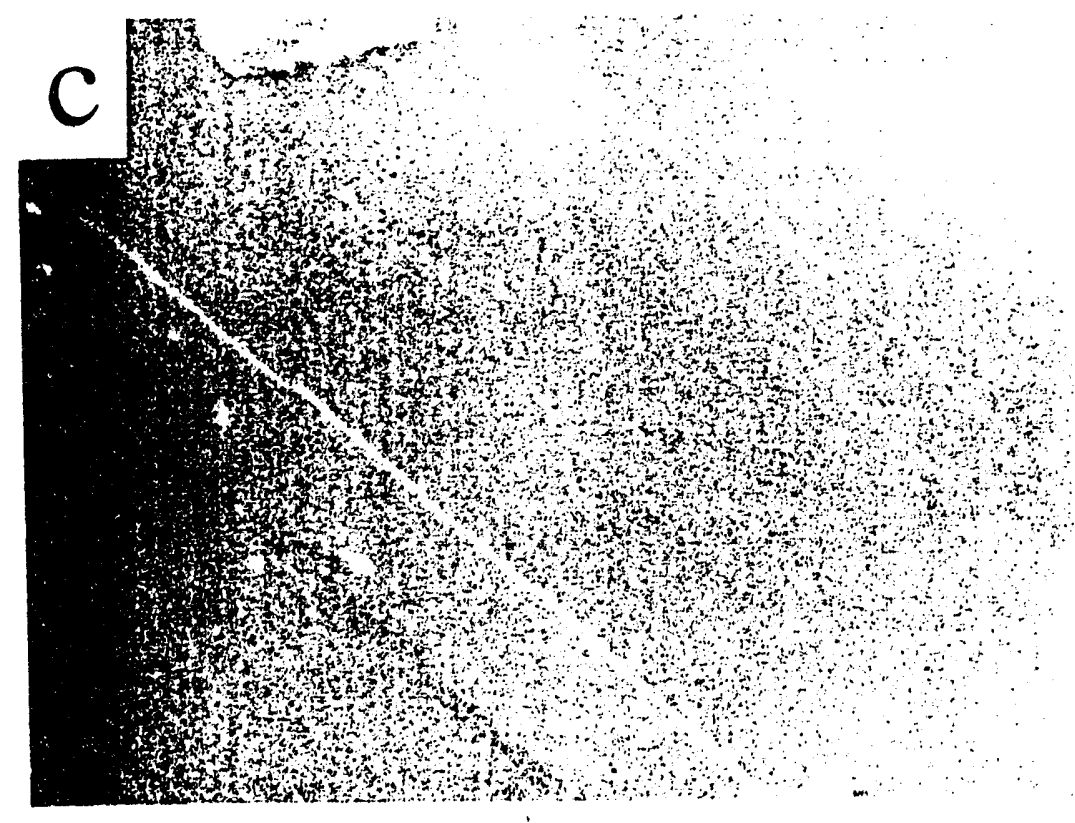

Figure 4 

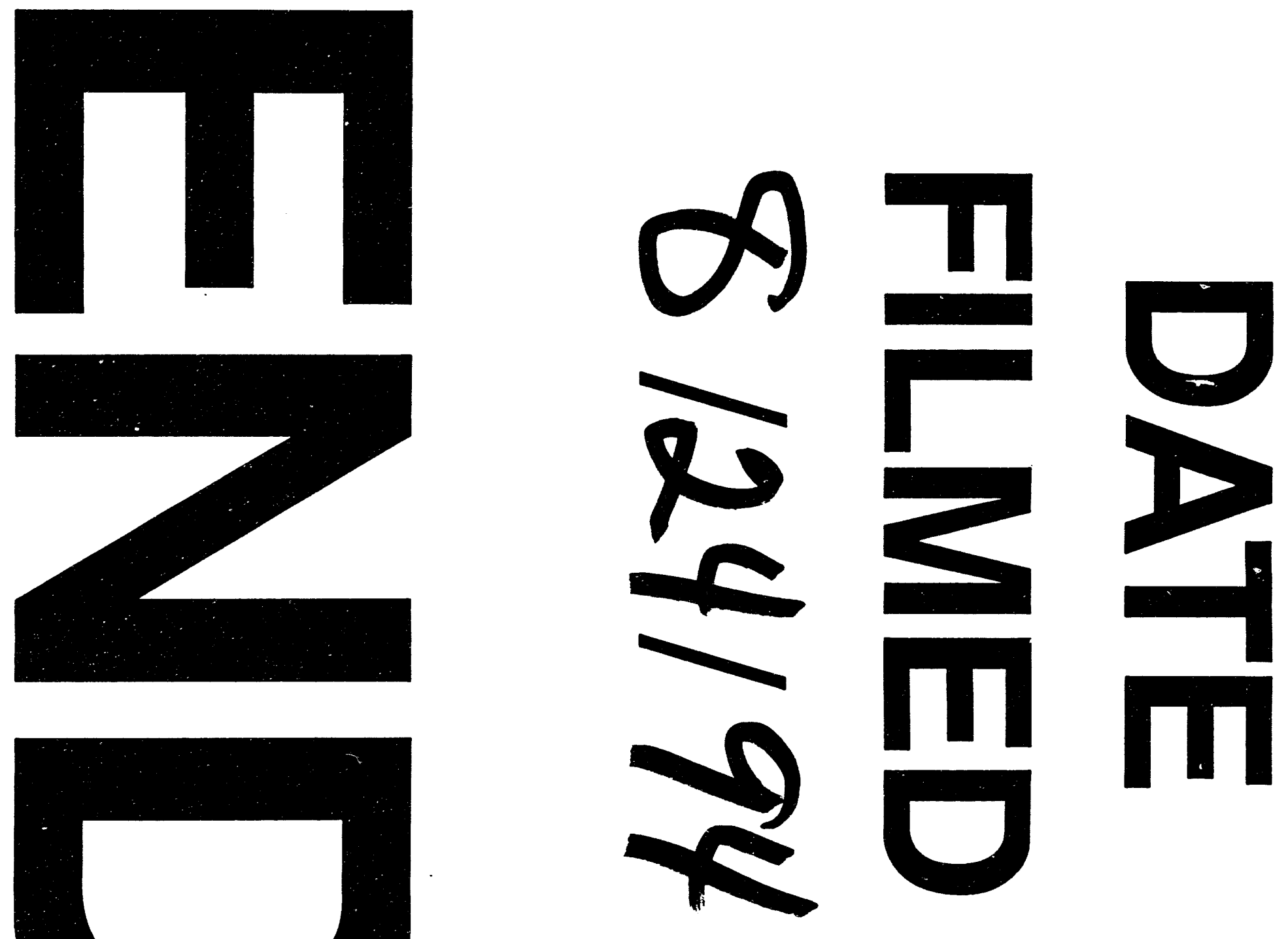
